Identity, religious spaces, and health 1

\title{
Stairway to heaven? (Ir)religious identity moderates the effects of immersion in religious spaces on self-esteem and self-perceived physical health
}

\author{
Renate Ysseldyk ${ }^{\mathrm{a}}$, S. Alexander Haslam ${ }^{\mathrm{b}, \mathrm{c}}$, and Thomas A. Morton ${ }^{\mathrm{c}}$ \\ Carleton University ${ }^{\mathrm{a}}$, The University of Queensland ${ }^{\mathrm{b}}$, and University of Exeter ${ }^{\mathrm{c}}$
}

Correspondence concerning this manuscript should be addressed to: Renate Ysseldyk, Department of Health Sciences, Carleton University, 1125 Colonel By Drive, Ottawa, K1S 5B6 Canada. Email: renate.ysseldyk@carleton.ca 
Identity, religious spaces, and health 2

\begin{abstract}
The present research explored how immersion in religious spaces influenced self-perceived psychological and physical health among Christians and Atheists. Study $1(N=97)$ provided preliminary evidence in that self-identified Christians reported higher self-esteem when they focused on their external environment outside a cathedral (versus a castle or shopping district), whereas Atheists reported higher self-esteem when they focused away from this religious environment. Study $2(N=124)$ followed up on these findings by immersing Christian and Atheist participants in virtual environments. Christians reported better physical health when immersed in a cathedral (versus a mosque or museum) compared to Atheists immersed in the cathedral, who reported the greatest health while disengaging from this religious place. These results suggest that immersion in spaces that reflect one's own religious beliefs and identity has positive consequences for health and well-being.
\end{abstract}

Keywords: identity, religion, place, health, well-being 
Identity, religious spaces, and health 3

\section{Highlights}

- We assessed whether immersion in religious spaces impacts self-reported health

- Christians reported better health and well-being when focused on a cathedral

- Atheists reported better health when focused away from religious environments

- Immersion in spaces reflecting religious identity can positively impact health 
Identity, religious spaces, and health 4

\section{Introduction}

Where we are affects how we feel—particularly when those places also reflect who we are. Indeed, previous research shows that identity-relevant spaces and symbols can have implications for psychological well-being (e.g., Bilewicz \& Klebaniuk, 2013; Curtis, 2010; Schmitt, Davies, Huang, Wright, 2010). In line with theories of place attachment and place identity (see Hopkins \& Dixon, 2006; Lewicka, 2011; Reicher, Hopkins, \& Harrison, 2006), certain physical places can hold great symbolic meaning for the individual (e.g., by representing significant emotional bonds; Droseltis \& Vignoles, 2010) and support individual psychological needs or motives (e.g., for self-esteem). In the present paper we argue that this may be especially true of religious spaces.

Given the dual social and belief-based elements to religious identities (for an overview, see Ysseldyk, Matheson, \& Anisman, 2010), religious spaces are not only physical embodiments of valued beliefs but are also places within which individuals interact with and connect to others with whom the share an important identity. Because of this, seeing one's religious identity reflected in physical spaces may be a uniquely stirring experience. Consistent with this idea, Schmitt and colleagues (2010) found that Christians subtly exposed to a Christmas tree reported greater positive affect and self-esteem compared to individuals who did not celebrate Christmas (Sikhs and Buddhists). Similarly, Bilewicz and Klebaniuk (2013) found that exposure to a crucifix was associated with less negative affect among highly-religious Roman Catholics, while the effect of this on less-religious Roman Catholics was negligible. Thus, in the same way that people value objects and ideas that affirm their identities (Morton, Haslam, Postmes, \& Ryan, 2006), places that reflect people's identities might confer positive value on the self, particularly 
Identity, religious spaces, and health 5

when those places have sacred meaning (Mazumdar \& Mazumdar, 2004; Ouellette, Kaplan, \& Kaplan, 2005).

The previously demonstrated effects of identity-relevant spaces and symbols are consistent with contemporary theorizing within the social identity tradition. One of the central tenets of social identity theory (Tajfel \& Turner, 1979) is that, in a range of contexts, individuals' self-concept is structured by their identification with meaningful social groups. Because of this, group membership has implications for individual self-regard. In particular, group memberships provide a framework for interpreting social reality (e.g., through shared group norms) and for establishing connections with similar others. Through these features, group membership can provide the individual with a sense of meaning, purpose, and social support, and therefore has the capacity to contribute positively to individual health and well-being (see Cruwys et al., 2014; Jetten, Haslam, \& Haslam, 2011).

Consistent with this analysis, group membership has been found to have a range of psychological benefits, including enhanced personal and collective self-esteem (Jetten et al., in press; Luhtanen \& Crocker, 1992; Tajfel \& Turner, 1979), and reduced symptoms of depression (Cruwys et al., 2013; Mossakowski, 2003). Moreover, the psychological effects of group membership extend to physical health and well-being (Cole, Kemeny, \& Taylor, 1997; Sani, Madhok, Norbury, Dugard, \& Wakefield, 2015), and can have consequences for symptom perceptions (St. Claire, Clift, \& Dumbelton, 2008), cortisol reactivity (Matheson \& Cole, 2004), cognitive capacity and memory decline (Jetten et al., 2011). Of course, the precise connection between group membership and mental and physical health also often depends on the social standing of one's group. Membership in stigmatized groups can have negative implications for well-being (Branscombe, Schmitt, \& Harvey, 1999) and threatening valued identities can trigger 
a host of negative affective and physical stress responses (e.g., Matheson, Gill, Kelly, \& Anisman, 2008; Townsend, Major, Gangi, \& Mendes, 2011).

Although numerous social identities can come to be valued by individuals, religious identification may be especially salient for many, given its foundation in a belief system that offers epistemological and ontological certainty (Ysseldyk et al., 2010, 2013). Moreover, much research has demonstrated a link between religion and both psychological and physical health. In addition to the benefits derived from religious group identity itself (Hayward \& Krause, 2014; Ysseldyk et al., 2013), such effects are customarily attributed to a range of factors, including health-enhancing practices, social support, and an increased sense of purpose, meaning, and selfefficacy (George, Ellison, \& Larson, 2002; George, Larson, Koenig, \& McCullough, 2000; Seybold \& Hill, 2001). Further to the ideological and social functions of religion, religious communities routinely also construct highly visible landmarks that serve as physical markers of their shared systems of beliefs (Haslam, Reicher, \& Platow, 2010). Indeed, the embodiment of social identities in space (e.g., through landmarks, buildings, and significant sites) serves as a physical affirmation of the viability and importance of one's social identity. As a result, contemplating, or being immersed in such places, is likely to be experienced as identity affirming and consequently bolster the self.

Conversely, finding oneself in places that challenge or negate a valued identity may be experienced as undermining social identity. In this regard, the reactions of Atheists may be unique in the context of religious spaces. Although many Atheists embrace an (ir)religious social identity linked to an explicit belief system — namely naturalistic materialism (Fales, 2007; Taylor, 2007) — their atheistic identity lacks the physical (e.g., churches, temples; de Botton, 2012) and spiritual infrastructure (e.g., congregations, prayer) that supports religious groups 
(Putnam \& Campbell, 2010; Ysseldyk et al., 2010). Accordingly, whereas religious people may experience health-promoting benefits when immersed in an identity-affirming place of worship (e.g., as observed among pilgrims to Lourdes or other places of religious significance; Pieper \& Van Uden, 1994; Tewari, Khan, Hopkins, Srinivasan, \& Reicher, 2012), Atheists might feel threatened in such a place.

\subsection{The Present Research}

In line with the ideas outlined above, the present research investigated whether immersion in spaces of religious significance influenced perceptions of psychological and physical health among Christians and Atheists. To this end, we evaluated responses across locations, (ir)religious groups, and levels of immersion in the space. Study 1 assessed participants who were experimentally primed to focus outwardly (immersed) versus inwardly (not immersed) at either a cathedral (a place with religious significance), a castle (another historic place but with no religious significance), or a shopping district (which had neither religious nor historical importance). Study 2 expanded on this by immersing participants in virtual environments, and by including religious spaces that were not expected to be identityaffirming for Christians (a mosque), yet might be for Atheists (a natural history museum). In so doing, the present research extends previous work (e.g., Bilewicz \& Klebaniuk, 2013; Schmitt et al., 2010) in several important ways, most notably by (1) assessing the effects of large-scale religious spaces rather than smaller-scale symbols, (2) evaluating direct immersion in a religious space, (3) comparing the effects of religious sites with those of historical non-religious places, and (4) comparing the responses of Christians to Atheists (rather than other religious groups). 
Identity, religious spaces, and health 8

\section{Study 1}

Study 1 took the form of a preliminary investigation of our ideas. The goal of this study was to compare the psychological well-being (i.e., self-esteem, mood) that Christians and Atheists reported at a religious place to the well-being they reported at other non-religious spaces (a castle and a shopping center). To enhance immersion in the physical space, some participants were asked to actively focus on (i.e., immerse themselves in) their external environment whereas others were asked to turn away from that environment and instead focus inwards on the self. Obviously, self-selection is an important issue when examining the psychological consequences of being in specific environments: people who feel uncomfortable in a space can simply leave it. However, manipulating the direction of people's attention (i.e., outward vs. inward) introduces some control over this, and allows us to disentangle the effects of simply being in a place (and ignoring it) versus being actively present in that place. It was expected that Christians immersed in the identity-affirming space (the cathedral) would report better psychological well-being relative to Atheists immersed in the religious space, and relative to Christians immersed in nonreligious spaces.

\subsection{Method}

2.1.1. Participants and Procedure. Participants ( 42 men, 55 women; $16-75$ years, $M=28.03$, $S D=12.64)$ were recruited at three outdoor locations in a British city: a cathedral $(n=32)$, a castle ( $n=34)$, and a shopping district ( $n=31)$. After giving informed consent for a study described as assessing "influences on well-being", participants were randomly assigned to one of two conditions designed to differentially manipulate immersion in the space. In one condition (immersion; $n=48$ ) the instructions requested that participants "take a moment to consider your external surroundings, that is, the buildings or landmarks around you" before completing the 
questionnaire. In the alternative condition (non-immersion; $n=49$ ) participants were instructed to consider "your internal feelings, that is, the thoughts or emotions within you". After completing the questionnaire and providing demographic information, including self-identification as Atheist ( $n=49)$ or Christian $(n=48)^{1}$, participants were thanked and debriefed.

\subsubsection{Measures}

2.1.2.1. Self-esteem. Three dimensions of state self-esteem (Heatherton \& Polivy, 2004) were measured, including appearance (6 items; e.g., "I am pleased with my appearance right now"; $\alpha=.81$ ), social (7 items; e.g., "I am worried about what other people think of me"; reversescored; $\alpha=.78$ ), and performance (7 items; e.g., "I feel confident about my abilities"; $\alpha=.77$ ) based esteem. Participants indicated how they thought about themselves "at that moment" on a scale from 1 (not at all) to 5 (extremely).

2.1.2.2. Mood. Current mood was reported using the Positive and Negative Affect Schedule, Short-Form (PANAS-SF, Thompson, 2007; Watson, Clark, \& Tellegen, 1988). Participants indicated how accurately each of 10 adjectives described their mood "at that moment" from 0 (not at all) to 6 (extremely), in terms of positive (e.g., determined, inspired; $\alpha=.82$ ) and negative affect (e.g., hostile, nervous; $\alpha=.81$ ).

\subsection{Results and Discussion}

2.2.1. Self-esteem. A multivariate analysis of covariance ${ }^{2}$ (MANCOVA) was conducted to assess participants' state self-esteem (appearance, performance, and social) as a function of their location (cathedral, castle, shopping district), (ir)religious group (Atheist, Christian), and level of immersion (immersion, non-immersion). This analysis revealed a significant multivariate threeway interaction, Pillai's $=0.188 ; F(6,164)=2.83, p=.012, \eta^{2}=.094$ (see Table 1 for descriptive statistics of each study variable across conditions). Inspection of the univariate effects indicated 
that this interaction was most evident on social self-esteem, $F(2,83)=5.32, p=.007, \eta^{2}=.114$, versus appearance esteem, $F(2,83)=2.74, p=.071, \eta^{2}=.062$, or performance esteem, $F(2,83)=1.65$, $p=.198, \eta^{2}=.038$. The social self-esteem interaction is depicted graphically in Figure 1 .

Consistent with predictions, there was no interaction between group membership and immersion at either the castle, $F(1,30)=2.03, p=.164, \eta^{2}=.063$, or the shopping district, $F(1,27)=0.17$, $p=.682, \eta^{2}=.006$. However, the interaction between group and immersion was significant at the cathedral, $F(1,28)=10.62, p=.003, \eta^{2}=.275$. Among Atheists, social self-esteem was higher when they focused inwardly in the presence of the cathedral, $F(1,83)=5.50, p=.021, \eta^{2}=.062$, whereas there was an opposing trend for Christians' social self-esteem to be higher when they focused outwardly at the cathedral, $F(1,83)=3.41, p=.068, \eta^{2}=.039$.

Thus, in line with previous research that has examined the impact of identity-affirming religious symbols on psychological well-being (e.g., Bilewicz \& Klebaniuk, 2013; Mazumdar \& Mazumdar, 2004; Schmitt et al., 2010), Christians' social self-esteem appeared to be bolstered when they immersed themselves in their physical surroundings at a cathedral relative to other non-religious locations. Conversely, in a religious place, Atheists' self-esteem was higher when they focused away from the space and instead focused inwardly on the self.

2.2.2. Mood. The analysis of mood revealed effects of different locations and immersion, but these were not contingent on (ir)religious group membership. Specifically, a MANCOVA ${ }^{3}$ assessing participants' (positive and negative) affect revealed a marginally significant multivariate interaction between location and immersion, Pillai's $=0.098 ; F(4,166)=2.14, p=.078$, $\eta^{2}=.049$, driven by a significant univariate interaction on negative affect, $F(2,83)=3.94, p=.023$, $\eta^{2}=.087$. Follow-up analyses indicated that when participants focused on their internal thoughts and feelings, negative affect did not differ across locations, $F(2,83)=0.49, p=.615, \eta^{2}=.012$. 
However, when they focused on their external surroundings (i.e., were immersed), $F(2,83)=9.02$, $p<.001, \eta^{2}=.178$, negative affect was significantly higher at the shopping $\operatorname{district}(M=2.62$; $S E=.31)$ than at the castle $(M=1.34 ; S E=.26 ; p=.002)$, and cathedral $(M=0.89 ; S E=.29 ; p<.001)$ - a pattern that likely reflected the physical features of the shopping center relative to the other spaces (e.g., crowding). Further to this, when negative affect was examined separately for each location, immersion in the space (compared with focusing inwardly) was associated with more negative affect when at the shopping center, $F(1,83)=15.91, p<.001, \eta^{2}=.161$, and castle, $F(1,83)=3.47, p=.066, \eta^{2}=.040$, but not at the cathedral, $F(1,83)=0.002, p=.967, \eta^{2}=.000$. These results may suggest that the cathedral had a buffering effect on negative emotions, such that all participants experienced less negative mood when focused on the cathedral relative to the other locations, irrespective of their (ir)religious group membership. At the same time, focusing on the features of the shopping centre appeared to be a particularly unpleasant experience for everyone. Importantly, controlling for mood did not affect the patterns reported above regarding selfesteem, suggesting that those effects were not attributable to mood.

\section{Study 2}

Study 1 provides some preliminary indication that immersion in places that affirm one's religious identity has the capacity to promote psychological well-being, in the sense that one's self-regard was enhanced. Most notably, Christians who actively immersed themselves at a religious place (a cathedral) tended to report higher social self-esteem than Christians immersed in non-religious spaces (a castle or shopping area). Conversely, Atheists reported higher social self-esteem when they focused their attention away from a religiously significant place and instead focused inwardly on the self. 
Identity, religious spaces, and health 12

Although these patterns provide some support for our hypothesis, they nonetheless have limitations. First, as noted in the above, people's presence in these spaces is self-selected. Although we were able to manipulate immersion around that, presumably people who found these spaces threatening (for identity reasons or otherwise), would avoid them and therefore not be included in our sample. This may explain why potentially deleterious effects of religiously incongruent spaces were not observed in this study (in contrast to Schmitt et al., 2010). Second, while social self-esteem is an interesting and important outcome (e.g., see Jetten et al., in press), it is useful to ask how deep these effects run. That is, are they limited to positive feelings about the self or do they extend to other indicators of psychological and physical health? Finally, while the data we collected in Study 1 allowed us a first exploration of the validity of our assumptions in a naturalistic setting, the sample was very small. This inevitably raises questions about the robustness of our observations.

To address these questions, and to further explore the generalizability of the observed effects of identity-congruent spaces, Study 2 tested whether these same patterns were evident (1) in another country, namely Canada, where the atheism-religion divide has been less pronounced; (2) when a specifically non-Christian religious space (i.e., a mosque) and a conceivably Atheistidentity-affirming space (i.e., a natural history museum) were included; (3) when participants were randomly assigned to these (virtual) spaces in the laboratory; (4) on a broader array of psychological well-being measures, including one more directly related to group life (i.e., collective self-esteem); and (5) when effects on self-perceived physical health were also considered following exposure to the space. As in Study 1, it was expected that Christians who were immersed in the identity-affirming space (a cathedral) would report better psychological 
and physical health relative to Atheists immersed in religious spaces, and relative to Christians immersed in non-identity-affirming (or identity-negating) spaces.

\subsection{Method}

3.1.1. Participants and Procedure. Participants (124 women ${ }^{4} ; 17-38$ years, $M=19.63, S D=2.90$ ) were recruited on the campus of a Canadian university for a study described as assessing the effects of "virtual tourism". Based on a pre-measure (administered several months in advance) that assessed religious group affiliation (or lack thereof), equal numbers of Christians and Atheists were assigned to one of three "virtual" locations that involved watching an edited online video (approximately 2:13 $\mathrm{min})$ of a cathedral $(n=41)$, a mosque $(n=41)$, or a museum $(n=42)$. To parallel the immersion manipulation in Study 1, immersion in the space was heightened by having some participants $(n=60)$ view their video through virtual reality goggles (HMD; Z800 3D-Visor, eMagin Corporation, Fishkill, New York) while being actively encouraged to imagine themselves in this place, whereas other participants $(n=64)$ simply viewed the video on a computer screen and were asked to focus primarily on the video quality. Following the video, participants responded to a questionnaire and provided demographic details, confirming their self-identification as Atheist $(n=55)$ or Christian $(n=69)$. After completing these measures, participants were thanked and debriefed.

\subsubsection{Measures}

3.1.2.1. Collective self-esteem (CSE). Luhtanen and Crocker's (1992) measure was modified for (ir)religious groups. Participants rated statements on public (e.g., "Others respect the religious group that I am a member of"; $\alpha=.74)$ and private esteem (e.g., "I feel good about the religious group that I belong to"; $\alpha=.91$ ), from 1 (strongly disagree) to 7 (strongly agree). Atheists were asked to consider the group membership they shared with other Atheists. 
Identity, religious spaces, and health 14

3.1.2.2. Self-esteem. As in Study 1, three dimensions of personal state self-esteem (Heatherton \& Polivy, 2004) were measured, including appearance $(\alpha=.84)$, social $(\alpha=.83)$, and performance $(\alpha=.84)$.

3.1.2.3. Mood. As in Study 1, current mood was reported using the PANAS (Watson et al., 1988). However, in this case a modified longer version (40 items) was used in order to assess a broader array of emotions, including shame $(\alpha=.87)$, anger $(\alpha=.80)$, anxiety $(\alpha=.86)$, sadness $(\alpha=.86)$, and positive affect $(\alpha=.84)$.

3.1.2.4. Physical health. Participants reported the state of their current physical health on a widely used single-item measure (Idler \& Benyamini, 1997). This involved rating one's health as "poor", "fair", "good", "very good", or "excellent", on a scale ranging from 1 to 5.

Importantly, Idler and Benyamini's (1997) review indicates that this measure is also a very good predictor of objective health (i.e., mortality).

\subsection{Results and Discussion}

3.2.1. Collective self-esteem. A MANOVA ${ }^{5}$ assessing differences in religious CSE (private and public) as a function of location (cathedral, mosque, museum), (ir)religious group (Atheist, Christian), and level of immersion (immersion, non-immersion) yielded no significant multivariate effects with the exception of a main effect for group, Pillai's $=0.319$; $F(2,111)=25.98, p<.001, \eta^{2}=.319$. Univariate effects indicated that this was particularly evident on public, $F(1,112)=55.38, p<.001, \eta^{2}=.319$, rather than private CSE, $F(1,112)=1.62, p=.206$, $\eta^{2}=.014$. Here, Christians $(M=5.52, S D=1.09)$ reported greater public CSE than Atheists ( $M=4.18, S D=0.99$ ), $p<.001$. This finding concurs with other research (Ysseldyk, Haslam, Matheson, \& Anisman, 2012) in which Christians report greater acceptance by other groups than do Atheists. 
Interestingly, the main effect of religious group membership on public CSE was also modified by a marginally significant interaction between group and location, $F(1,112)=2.91$, $p=.058, \eta^{2}=.049$. Examination of this revealed that although Christians consistently reported higher public CSE than Atheists, this was especially pronounced after watching the video of the cathedral (an identity-affirming place for Christians), $F(1,112)=37.07, p<.001, \eta^{2}=.249$, but was less apparent after having viewed the museum video (an identity-irrelevant space), $F(1,112)=12.76, p=.001, \eta^{2}=.102$, and even less so after viewing the mosque video (an identitynegating space) $F(1,112)=8.22, p=.005, \eta^{2}=.068$.

3.2.2. Self-esteem. A MANOVA assessing differences in self-esteem as a function of location, (ir)religious group, and immersion revealed no significant differences with the exception of a univariate main effect of location on social self-esteem, $F(2,112)=3.11, p=.048$, $\eta^{2}=.053$. Specifically, participants reported greater social self-esteem after viewing the video of the cathedral $(M=3.78, S D=0.58)$ compared to the museum $(M=3.36, S D=0.75, p=.015)$, but not the mosque $(M=3.52, S D=0.82, p=.136)$. Although this effect of location on social self-esteem was not altered by participants' level of immersion or (ir)religious group as it was in Study 1, it is worth noting that collective self-esteem was measured first in Study 2 (and not at all in Study 1), and likely reflected the feelings that were most relevant in this group-based context.

3.2.3. Mood. A MANOVA assessing differences in mood as a function of location, (ir)religious group, and immersion revealed no significant multivariate or univariate effects. As in Study 1, this suggests that any effects of the independent variables are unlikely to be attributable to mood alone.

3.2.4. Physical health. An ANCOVA assessing participants' self-reported physical health (controlling for actual physical activity and illness) revealed a marginally significant three-way 
interaction between location, (ir)religious group, and immersion, $F(2,111)=2.95, p=.055, \eta^{2}=.052$ (see Table 2 for descriptive statistics of each study variable across conditions). As depicted graphically in Figure 2, follow-up analyses revealed that the interaction between immersion and group was non-significant when viewing the video of the mosque, $F(1,36)=0.08, p=.778$, $\eta^{2}=.001$, or museum, $F(1,37)=0.60, p=.445, \eta^{2}=.009$, but was significant when viewing the video of the cathedral, $F(1,36)=7.63, p=.009, \eta^{2}=.222$. When immersed in the cathedral (i.e., wearing virtual reality goggles), Christians reported better health than Atheists, $F(1,111)=6.05, p=.015$, $\eta^{2}=.052$. Although Atheists appeared to report better health than Christians in the non-immersion condition at the cathedral (see Figure 2), mirroring the patterns found in Study 1, this difference was not significant, $F(1,111)=1.24, p=.268, \eta^{2}=.011$.

Looked at differently, Atheists who were not immersed at the cathedral reported better physical health than Atheists who were immersed at the cathedral, $F(1,111)=4.02, p=.047$, $\eta^{2}=.035$. Once again, there appeared to be a trend for the reverse pattern among Christians (those immersed at the cathedral tended to report better health than those non-immersed; see Figure 2), but this difference did not reach significance, $F(1,111)=2.34, p=.129, \eta^{2}=.021$.

Further to this, it is also interesting to note the patterns that emerged between immersion and location when this interaction was examined separately for the two (ir)religious groups. Here, Christians who were immersed at the cathedral perceived their physical health to be better than Christians immersed at either the mosque ( $p=.031)$ or the museum $(p=.021), F(2,111)=3.42$, $p=.036, \eta^{2}=.058$. However, there were no such differences among Atheists, $F(2,111)=0.42$, $p=.655, \eta^{2}=.008$. Taken together, immersion in an identity-affirming religious space thus appeared to augment Christians' perceptions of their physical health. 
Identity, religious spaces, and health 17

\section{General Discussion}

Together, the findings from the two studies reported here provide some preliminary evidence that immersion in identity-affirming places can influence perceptions of both psychological and physical health. In conducting this research, we were particularly interested in the effects of spaces that could affirm (or threaten) group identity among individuals adhering to a religious belief system, namely Christians, and individuals who did not adhere to any formal religious belief system, namely Atheists. As expected, Christians reported the highest levels of health and well-being when immersed in a space that reflected that religious identity (a cathedral). In contrast, Atheists generally reported better well-being when not immersed in that space, either as a result of having their attention drawn away from their physical environment (Study 1) or following instructions that encouraged them to take a detached perspective on that environment (Study 2). This was the case across two studies, irrespective of country (Britain or Canada), sample characteristics (community adults or students), and whether immersion in the space entailed participants' physical (Study 1) or virtual (Study 2) presence. Specifically, Christians reported higher self-esteem (Study 1) and better physical health (Study 2) when immersed at the cathedral relative to other locations, including those that had comparable historical significance (a castle) or links to another religious faith (a mosque). In contrast, Atheists' self-esteem and self-reported physical health was greatest when they focused away from that religious environment.

Interestingly, both personal (Study 1) and collective (Study 2) self-esteem effects were restricted to the social aspects of esteem (e.g., feeling good around others; Heatherton \& Polivy, 2004; or one's group being viewed in a positive light by others; Luhtanen \& Crocker, 1992), rather than more private feelings about one's appearance or ability, or about the group to which 
Identity, religious spaces, and health 18

one belongs. Although the personal self-esteem interactions observed in Study 1 did not emerge as expected in Study 2, collective self-esteem was measured before personal self-esteem in the latter study. It seems plausible that collective self-esteem was most critical in terms of participants' self-regard in these group-based spaces, and that measuring this first may have limited any subsequent effect on personal self-esteem. Alternatively, it may have been that personal self-esteem was more relevant in the public spaces investigated in Study 1, and less relevant in the contrived laboratory space investigated in Study 2. Nonetheless, taken together these findings suggest that the role of identity-affirming places in underscoring individual wellbeing may reflect the ability of these places to signal acceptance within the broader social context, either of the individual self (Study 1) or one's group (Study 2). Yet, the meaningfulness of these spaces also seems to be physically internalized, as evidenced by Christians' health perceptions. Much like other research demonstrating the importance of social identity for symptom appraisals (St. Claire et al., 2008), or analgesic effects attributed to the reappraisal of pain among Catholics (compared to Atheists) who viewed the Virgin Mary (compared to a similar non-religious picture; Wiech et al., 2009), reappraisal of one's physical health may have been fostered by being in an identity-affirming religious space.

It is also noteworthy that, in both studies, Atheists appeared to report effects of immersion in the cathedral that were the very opposite of those observed for Christians. That is, Atheists felt better in this space when given a non-immersive instruction - that is, to ignore the space they were in or observing. The positive effects on non-believers of being in, but not being actively engaged with, a religious place were not entirely anticipated in this research. Speculatively, turning away or disengaging from such spaces may allow the individual to reassert identity in the face of places that would otherwise negate it. It is interesting to note, 
Identity, religious spaces, and health 19

however, that these effects among Atheists were evident at a cathedral but not a mosque, perhaps suggesting disengagement with Christian symbols (and the cultural hegemony embedded therein) in particular. Nonetheless, contrary to previous research suggesting that some religious symbols are prone to harm non-Christians (e.g., Christmas trees; Schmitt et al., 2010), negative affect appeared to be buffered by focussing on the cathedral in Study 1, regardless of (ir)religious group membership, relative to the shopping district (not surprisingly) or even the castle (presumably a British identity-affirming place), and no differences on positive or negative affect were found in Study 2. Likewise, social self-esteem seemed to be enhanced by viewing the cathedral video in Study 2, irrespective of group membership or immersion, relative to viewing the museum.

A strength of the present research is the combination of natural and virtual locations to explore responses to space. Another strength is the inclusion of focus manipulations to disentangle the effects of being in a place (perhaps due to self-selection) versus actively attending to or immersing oneself in that space. Of course, these strengths are also balanced by weaknesses. In particular, it should also be noted that sample sizes in both studies were relatively small. In part, this was due to seasonal considerations in Study1 (i.e., outdoor data collection limited by weather conditions in England) and the time-consuming paradigm used in Study 2 (which involved individual testing and the use of technical equipment). Despite this caveat, the use of different samples and methods, and the convergence of patterns across studies, provides some confidence about their robustness - and provides a positive signal to researchers wanting to follow up on these ideas.

Taken together, these findings extend previous research that points to the well-being effects of exposure to religious symbols (e.g., Bilewicz \& Klebaniuk, 2013; Mazumdar \& 
Identity, religious spaces, and health 20

Mazumdar, 2004; Schmitt et al., 2010) and participation in religious rituals on health and wellbeing (Khan et al., 2014; Ouellette et al., 2005; Tewari et al., 2012). Consistent with theories of place identity and attachment (e.g., Hopkins \& Dixon, 2006; Lewicka, 2011; Reicher et al., 2006), as well as the literature on religion (and religious identity) and health (e.g., George et al., 2000, 2002; Hayward \& Krause, 2014; Seybold \& Hill, 2001; Ysseldyk et al., 2013) our studies demonstrate that immersion in identity-affirming religious spaces can also enhance selfperceptions of both psychological and physical health. Indeed, although such well-being effects are often dismissed as a "Lourdes effect", akin to a placebo (Chassagnon, 1988; Rush \& Thase, 2002), the present research suggests that these kinds of effects may be experienced at a much deeper level than such an analysis would imply. For the Christians in our research, there was evidence that immersion in identity-affirming religious environments had positive effects that were marked in perceptions of both psychological and physical health. The exact connections between physical spaces, the social properties of these, and individual bodily and mental experiences seem worthy of further investigation.

In this regard, it is pertinent to note that although secular spaces abound, these are often less psychologically striking than religious spaces (de Botton, 2012). This is signalled by the fact that in many villages, towns, and cities it is common for the most prominent buildings (e.g., those that dominate the skyline or that define the center) to be religious. In this way, these structures lend material form to religious identity and provide hard evidence of its social importance and power. Accordingly, for people who identify with the religious group that these buildings reflect, being immersed in such spaces may represent something of a physical "stairway to heaven" - making them feel better not only about the world, but also about themselves. In other words, it appears that religious spaces and their associated social identities 
Identity, religious spaces, and health 21

are mutually sustaining. For just as the space is brought to life by the identity, so too the identity (and through this the self) is brought to life by the space. 
Identity, religious spaces, and health 22

\section{References}

Bilewicz, M. \& Klebaniuk, J. (2013). Psychological consequences of religious symbols in public space: Crucifix display at a public university. Journal of Environmental Psychology, 35, 1017.

Branscombe, N. R., Schmitt, M. T., \& Harvey, R. D. (1999). Perceiving pervasive discrimination among African Americans: Implications for group identification and well-being. Journal of Personality and Social Psychology, 77, 125-149.

Chassagnon, C. (1988). Les miracles de Lourdes. Psychologie Medicale, 20, 653-656.

Cole, S. W., Kemeny, M. E., \& Taylor, S. E. (1997). Social identity and physical health: Accelerated HIV progression in rejection-sensitive gay men. Journal of Personality and Social Psychology, 72, 320-335.

Cruwys, T., Dingle, G., Haslam, S. A., Haslam, C., Jetten, J., \& Morton, T. (2013). Social group memberships protect against future depression, alleviate depression symptoms, and prevent depression relapse. Social Science and Medicine, 98, 179-186. doi.org/10.1016/j.socscimed.2013.09.013

Cruwys, T., Haslam, S. A., Dingle, G. A., Haslam, C., \& Jetten, J. (2014). Depression and social identity: An integrative review. Personality and Social Psychology Review, 8, 215-238. doi:10.1177/1088868314523839

Curtis, S. (2010). Space, place, and mental health. Ashgate.

de Botton, A. (2012). Religion for Atheists: A Non-believer's Guide to the Uses of Religion. Pantheon Books.

Droseltis, O. \& Vignoles, V. L. (2010). Towards an integrative model of place identification: Dimensionality and predictors of intrapersonal-level place preferences. Journal of Environmental Psychology, 30, 23-34. 
Fales, E. (2007). Naturalism and physicalism. In M. Martin (Ed.), The Cambridge companion to atheism (pp. 118-134). Cambridge University Press.

George, D., \& Mallery, M. (2010). SPSS for Windows Step by Step: A Simple Guide and Reference, 17.0 update $\left(10^{\text {th }}\right.$ ed.) Boston: Pearson.

George, L. K., Ellison, C. G., \& Larson, D. B. (2002). Explaining the relationships between religious involvement and health. Psychological Inquiry, 13(3), 190-200.

George, L. K., Larson, D. B., Koenig, H. G., \& McCullough, M. E. (2000). Spirituality and health: What we know, what we need to know. Journal of Social and Clinical Psychology, 19(1), 102-116.

Haslam, S. A., Reicher, S. D., \& Platow, M. J. (2010). The new psychology of leadership: Identity, influence and power. Psychology Press.

Hayward, R. D., \& Krause, N. (2014). Religion, mental health, and well-being: Social aspects. Religion, personality, and social behavior. (pp. 255-280) Psychology Press, New York, NY.

Heatherton, T. F. \& Polivy, J. (1991). Development and validation of a scale for measuring state self-esteem. Journal of Personality and Social Psychology, 60, 895-910.

Hopkins, N. \& Dixon, J. (2006). Space, place, and identity: Issues for political psychology. Political Psychology, 27, 173-185.

Idler, E. L. \& Benyamini, Y. (1997). Self-rated health and mortality: A review of twenty-seven community studies. Journal of Health and Social Behavior, 38, 21-37.

Jetten, J., Branscombe, N. R., Haslam, S. A., Haslam, C., Cruwys, T., Jones, J. M., Cui, L., Dingle, G., Liu, J., Murphy, S. C., Thai, A., Walter, Z., \& Zhang, A. (in press). Having a lot of a good thing: Multiple important group memberships as a source of self-esteem. PLOS ONE. 
Jetten, J. C., Haslam, C. \& Haslam, S. A. (2011). The social cure: Identity, health and wellbeing. Hove, UK: Psychology Press.

Khan, S. S., Hopkins, N., Reicher, S., Tewari, S., Srinivasan, N., \& Stevenson, C. (2014). Shared identity predicts enhanced health at a mass gathering. Group Processes \& Intergroup Relations.

Kling, K. C., Hyde, J. S., Showers, C. J., \& Buswell, B. N. (1999). Gender differences in selfesteem: A meta-analysis. Psychological Bulletin, 125, 470-500.

Lewicka, M. (2011). Place attachment: How far have we come in the last 40 years? Journal of Environmental Psychology, 31, 207-230.

Luhtanen, R. \& Crocker, J. (1992). A collective self-esteem scale: Self-evaluation of one's social identity. Personality and Social Psychology Bulletin, 18, 302-318.

Matheson, K., Gill, R., Kelly, O., \& Anisman, H. (2008). Cortisol and cardiac reactivity in the context of sex discrimination: The moderating effects of mood and perceived control. The Open Psychology Journal, 1, 1-10.

Mazumdar, S. \& Mazumdar, S. (2004). Religion and place attachment: A study of sacred places. Journal of Environmental Psychology, 24, 385-397.

Merz, E. L., Malcarne, V. L., Roesch, S. C., Ko, C. M., Emerson, M., Roma, V. G., \& Sadler, G. R. (2013). Psychometric Properties of Positive and Negative Affect Schedule (PANAS) Original and Short Forms in an African American Community Sample. Journal of Affective Disorders, 151(3), 942-949. http://doi.org/10.1016/j.jad.2013.08.011

Morton, T. A., Haslam, S. A., Postmes, T., \& Ryan, M. K. (2006). We value what values us: The appeal of identity-affirming science. Political Psychology, 27, 823-838. 
Mossakowski, K. N. (2003). Coping with perceived discrimination: Does ethnic identity protect mental health? Journal of Health and Social Behavior, 44, 318-331.

Ouellette, P., Kaplan, R., \& Kaplan, S. (2005). The monastery as a restorative environment. Journal of Environmental Psychology, 25(2), 175-188.

Pieper, J. Z. T. \& Van Uden, M. H. F. (1994). Lourdes: A place of religious transformations? The International Journal for the Psychology of Religion, 4, 91-104.

Putnam, R. D. \& Campbell, D. E. (2010). American grace: How religion divides and unites us. New York: Simon \& Schuster.

Reckelhoff, J. F. (2001). Gender differences in the regulation of blood pressure. Hypertension, 37, 1199-1208.

Reicher, S., Hopkins, N., \& Harrison, K. (2006). Social identity and spatial behaviour: The relationship between national category salience, the sense of home, and labour mobility across national boundaries. Political Psychology, 27, 247-263.

Relph, E. (1976). Place and placelessness. London: Pion.

Rush, A. J., \& Thase, M. E. (2002). Psychotherapies for depressive disorders: A review. In M. Maj \& N. Sartorius (Eds.), Depressive disorders, $2^{\text {nd }}$ edition (pp.161-206). John Wiley \& Sons Ltd: England.

Sani, F., Madhok, V., Norbury, M., Dugard, P., \& Wakefield, J. R. (2015). Greater number of group identifications is associated with healthier behaviour: Evidence from a Scottish community sample. British Journal of Health Psychology.

Schmitt, M. T., Davies, K., Huang, M., \& Wright, S. C. (2010). Identity moderates the effects of Christmas displays on mood, self-esteem, and inclusion. Journal of Experimental Social Psychology, 46, 1017-1022. 
Seybold, K. S., \& Hill, P. C. (2001). The role of religion and spirituality in mental and physical health. Current Directions in Psychological Science, 10(1), 21-24.

St Claire, L., Clift, A., \& Dumbelton, L. (2008). How do I know what I feel? Evidence for the role of self-categorisation in symptom perceptions. European Journal of Social Psychology, $38,173-186$.

Taylor, C. (2007). A secular age. Harvard University Press.

Tajfel, H., \& Turner, J. (1979). An integrative theory of intergroup conflict. In W. Austin \& S. Worchel (Eds.), The social psychology of intergroup relations (pp. 33-47). CA: Brooks/Cole.

Tewari, S., Khan, S., Hopkins, N., Srinivasan, N., \& Reicher, S. (2012) Participation in mass gatherings can benefit well-being: Longitudinal and control data from a North Indian Hindu pilgrimage event. PLoS ONE 7(10): e47291. doi:10.1371/journal.pone.0047291

Thompson, E. R. (2007). Development and validation of an internationally reliable short-form of the positive and negative affect schedule. Journal of Cross Cultural Psychology, 38, 227242.

Townsend, S. S. M., Major, B., Gangi, C. E., \& Mendes, W. B. (2011). From "in the air" to "under the skin": Cortisol responses to social identity threat. Personality and Social Psychology Bulletin, 37, 151-164.

Watson, D., Clark, L. A., \& Tellegen, A. (1988). Development and validation of brief measures of positive and negative affect: The PANAS scales. Journal of Personality and Social Psychology, 54, 1063-1070.

Wiech, K., Farias, M., Kahane, G., Shackel, N., Tiede, W., \& Tracey, I. (2009). An fMRI study measuring analgesia enhanced by religion as a belief system. Pain, 139, 467-476. 
Ysseldyk, R., Haslam, S. A., \& Haslam, C. (2013). Abide with me: Religious group identification amongst older adults promotes health and well-being by maintaining multiple group memberships. Aging and Mental Health, 17, 869-879. doi:10.1080/13607863.2013.799120

Ysseldyk, R., Haslam, S. A., Matheson, K., \& Anisman, H. (2012). Love thine enemy? Evidence that (ir)religious identification can promote outgroup tolerance under threat. Group Processes and Intergroup Relations, 15, 105-117.

Ysseldyk, R., Matheson, K. \& Anisman, H. (2010). Religiosity as identity: Toward an understanding of religion from a social identity perspective. Personality and Social Psychology Review, 14, 60-71. 
Identity, religious spaces, and health 28

\section{Acknowledgements}

Thanks to Dr. Hymie Anisman, Dr. Kim Matheson, and Dr. Michael Wohl for their laboratory and research support. Our appreciation to Kaitlyn Chambers, James Crisp, Mariya Davydenko, Talib Karamally, Jake Holiday, Jesse Howell, Opal McInnis, Ashlee Mulligan, Courtney Ostrega, and Sonya Saroyan for their assistance with data collection. This research was supported by the Canadian Institute for Advanced Research. 
Table 1

Descriptive Statistics for Variables in Study 1 (Means, SEs)

\begin{tabular}{|c|c|c|c|c|}
\hline & \multicolumn{2}{|c|}{ Christians } & \multicolumn{2}{|c|}{ Atheists } \\
\hline & Immersed & Not immersed & Immersed & Not immersed \\
\hline Cathedral & $(n=9)$ & $(n=7)$ & $(n=7)$ & $(n=9)$ \\
\hline \multicolumn{5}{|l|}{ Self-esteem } \\
\hline Social & $4.25(0.25)$ & $3.51(0.31)$ & $3.37(0.33)$ & $4.36(0.26)$ \\
\hline Appearance & $3.22(0.27)$ & $3.11(0.34)$ & $2.60(0.35)$ & $3.39(0.29)$ \\
\hline Performance & $3.48(0.24)$ & $3.67(0.30)$ & $2.94(0.31)$ & $3.05(0.25)$ \\
\hline \multicolumn{5}{|l|}{ Mood } \\
\hline Positive & $2.93(0.41)$ & $2.98(0.51)$ & $2.10(0.53)$ & $1.82(0.44)$ \\
\hline Negative & $0.61(0.34)$ & $1.07(0.42)$ & $0.96(0.44)$ & $0.49(0.36)$ \\
\hline Castle & $(n=10)$ & $(n=8)$ & $(n=8)$ & $(n=8)$ \\
\hline \multicolumn{5}{|l|}{ Self-esteem } \\
\hline Social & $2.97(0.25)$ & $3.50(0.28)$ & $3.78(0.28)$ & $3.50(0.30)$ \\
\hline Appearance & $3.07(0.27)$ & $2.93(0.31)$ & $3.47(0.31)$ & $3.29(0.33)$ \\
\hline Performance & $3.13(0.24)$ & $3.27(0.27)$ & $3.52(0.27)$ & $3.27(0.29)$ \\
\hline \multicolumn{5}{|l|}{ Mood } \\
\hline Positive & $3.37(0.41)$ & $2.67(0.46)$ & $2.92(0.46)$ & $2.41(0.49)$ \\
\hline Negative & $0.89(0.34)$ & $0.44(0.38)$ & $1.54(0.38)$ & $0.72(0.41)$ \\
\hline Shops & $(n=7)$ & $(n=7)$ & $(n=7)$ & $(n=10)$ \\
\hline \multicolumn{5}{|l|}{ Self-esteem } \\
\hline Social & $2.58(0.32)$ & $3.64(0.31)$ & $2.86(0.30)$ & $3.68(0.24)$ \\
\hline Appearance & $2.50(0.36)$ & $3.42(0.33)$ & $3.31(0.33)$ & $3.01(0.26)$ \\
\hline Performance & $2.44(0.31)$ & $3.68(0.29)$ & $3.33(0.29)$ & $3.25(0.23)$ \\
\hline \multicolumn{5}{|l|}{ Mood } \\
\hline Positive & $2.43(0.53)$ & $2.68(0.50)$ & $3.97(0.49)$ & $2.14(0.39)$ \\
\hline Negative & $2.96(0.44)$ & $0.86(0.41)$ & $1.93(0.41)$ & $0.88(0.33)$ \\
\hline
\end{tabular}


Table 2

Descriptive Statistics for Variables in Study 2 (Means, SEs)

\begin{tabular}{|c|c|c|c|c|}
\hline & \multicolumn{2}{|c|}{ Christians } & \multicolumn{2}{|c|}{ Atheists } \\
\hline & Immersed & Not immersed & Immersed & Not immersed \\
\hline Cathedral & $(n=11)$ & $(n=12)$ & $(n=9)$ & $(n=9)$ \\
\hline \multicolumn{5}{|l|}{ CSE } \\
\hline Public & $5.73(0.31)$ & $5.92(0.29)$ & $3.37(0.34)$ & $4.33(0.34)$ \\
\hline Private & $5.58(0.41)$ & $5.72(0.39)$ & $5.26(0.45)$ & $5.41(0.45)$ \\
\hline \multicolumn{5}{|l|}{ Self-esteem } \\
\hline Social & $3.64(0.22)$ & $4.20(0.21)$ & $3.41(0.24)$ & $3.78(0.24)$ \\
\hline Appearance & $3.32(0.23)$ & $3.75(0.22)$ & $3.48(0.25)$ & $3.17(0.25)$ \\
\hline Performance & $3.95(0.21)$ & $4.06(0.20)$ & $3.67(0.23)$ & $3.46(0.23)$ \\
\hline \multicolumn{5}{|l|}{ Mood } \\
\hline Positive & $1.22(0.38)$ & $1.72(0.36)$ & $1.27(0.42)$ & $0.84(0.42)$ \\
\hline Shame & $0.16(0.18)$ & $0.06(0.18)$ & $0.22(0.20)$ & $0.44(0.21)$ \\
\hline Anger & $0.09(0.21)$ & $0.19(0.20)$ & $0.11(0.23)$ & $0.53(0.23)$ \\
\hline Anxiety & $0.27(0.35)$ & $0.71(0.33)$ & $0.67(0.38)$ & $1.00(0.38)$ \\
\hline Sadness & $0.56(.027)$ & $0.25(0.26)$ & $0.33(0.30)$ & $1.07(0.30)$ \\
\hline Physical health & $4.09(0.26)$ & $3.54(0.25)$ & $3.15(0.28)$ & $3.96(0.28)$ \\
\hline Mosque & $(n=11)$ & $(n=11)$ & $(n=9)$ & $(n=10)$ \\
\hline \multicolumn{5}{|l|}{ CSE } \\
\hline Public & $5.39(0.31)$ & $5.39(0.31)$ & $4.41(0.34)$ & $4.53(0.33)$ \\
\hline Private & $5.67(0.41)$ & $5.36(0.41)$ & $5.44(0.45)$ & $5.73(0.43)$ \\
\hline \multicolumn{5}{|l|}{ Self-esteem } \\
\hline Social & $3.61(0.22)$ & $3.44(0.22)$ & $3.51(0.24)$ & $3.50(0.23)$ \\
\hline Appearance & $3.09(0.23)$ & $3.21(0.23)$ & $3.24(0.25)$ & $3.62(0.24)$ \\
\hline Performance & $3.78(0.21)$ & $3.66(0.21)$ & $3.79(0.23)$ & $3.71(0.22)$ \\
\hline \multicolumn{5}{|l|}{ Mood } \\
\hline Positive & $1.40(0.39)$ & $1.44(0.39)$ & $1.11(0.42)$ & $1.72(0.40)$ \\
\hline Shame & $0.14(0.19)$ & $0.16(0.19)$ & $0.00(0.21)$ & $0.18(0.20)$ \\
\hline Anger & $0.41(0.21)$ & $0.27(0.21)$ & $0.25(0.23)$ & $0.30(0.22)$ \\
\hline Anxiety & $1.55(0.35)$ & $1.26(0.35)$ & $1.11(0.39)$ & $0.45(0.37)$ \\
\hline Sadness & $1.00(0.27)$ & $0.49(0.27)$ & $0.20(0.30)$ & $0.54(0.28)$ \\
\hline Physical health & $3.30(0.26)$ & $3.69(0.26)$ & $3.18(0.28)$ & $3.46(0.27)$ \\
\hline Museum & $(n=11)$ & $(n=13)$ & $(n=9)$ & $(n=9)$ \\
\hline \multicolumn{5}{|l|}{ CSE } \\
\hline Public & $5.73(0.31)$ & $4.97(0.29)$ & $4.19(0.34)$ & $4.22(0.34)$ \\
\hline Private & $5.85(0.41)$ & $5.39(0.38)$ & $4.67(0.45)$ & $5.19(0.45)$ \\
\hline \multicolumn{5}{|l|}{ Self-esteem } \\
\hline Social & $3.46(0.22)$ & $3.33(0.20)$ & $3.19(0.24)$ & $3.46(0.24)$ \\
\hline Appearance & $3.32(0.23)$ & $3.15(0.21)$ & $3.46(0.25)$ & $3.19(0.25)$ \\
\hline Performance & $3.43(0.21)$ & $3.53(0.19)$ & $3.62(0.23)$ & $3.78(0.23)$ \\
\hline
\end{tabular}


Identity, religious spaces, and health 31

\begin{tabular}{lllll}
\hline Mood & & & & \\
$\quad$ Positive & $1.16(0.38)$ & $1.70(0.35)$ & $1.49(0.42)$ & $1.38(0.42)$ \\
Shame & $0.07(0.19)$ & $0.44(0.17)$ & $0.11(0.21)$ & $0.53(0.21)$ \\
Anger & $0.23(0.21)$ & $0.65(0.19)$ & $0.25(0.23)$ & $0.58(0.23)$ \\
Anxiety & $0.71(0.35)$ & $1.25(0.32)$ & $1.14(0.39)$ & $1.17(0.39)$ \\
Sadness & $0.15(0.27)$ & $0.72(0.25)$ & $0.22(0.30)$ & $0.80(0.30)$ \\
Physical health & $3.23(0.26)$ & $3.38(0.24)$ & $3.49(0.28)$ & $3.29(0.28)$ \\
\hline
\end{tabular}


Figure 1

Social self-esteem as a function of group identity, location, and immersion in Study 1

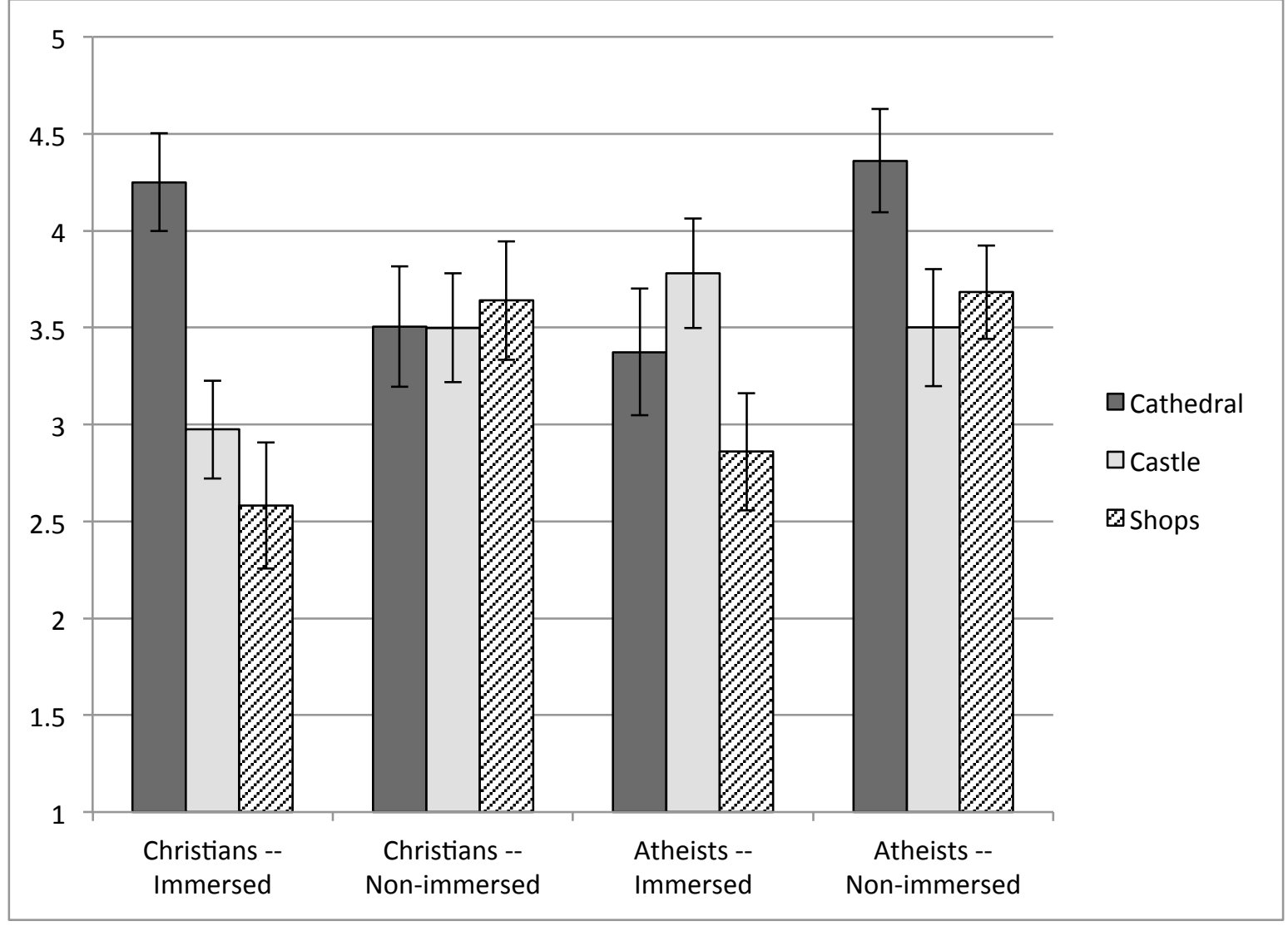

Note. Error bars denote standard error. 
Figure 2

Physical health as a function of group identity, location, and immersion in Study 2

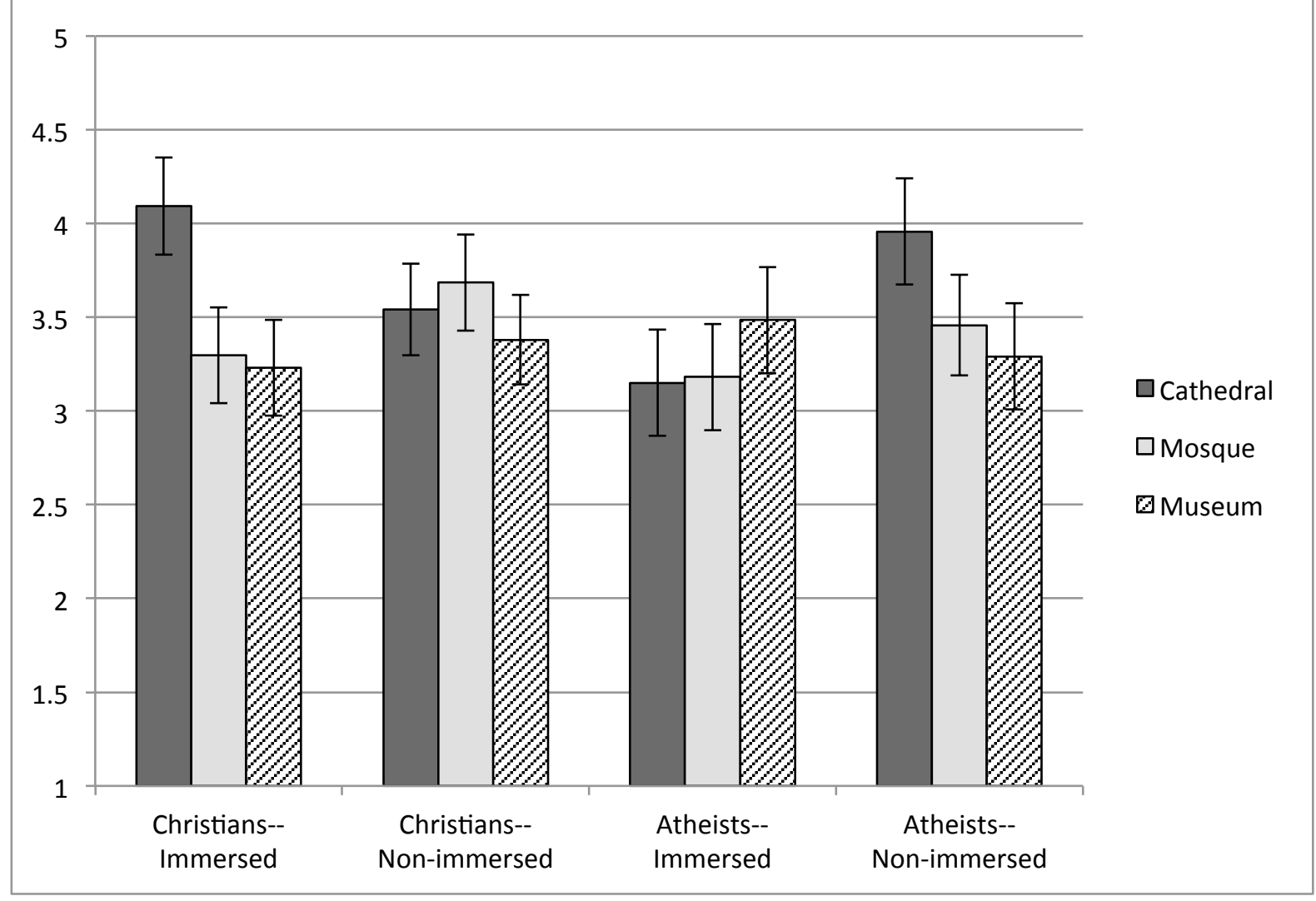

Note. Error bars denote standard error. 
Identity, religious spaces, and health 34

\section{Footnotes}

1. Perhaps unremarkably given the region of England in which Study 1 was conducted, approximately equal numbers of Christians and Atheists participated, and were equally distributed across the study conditions.

2. Gender was included as a covariate in Study 1, given previous research suggesting consistent differences in self-esteem (Kling, Hyde, Showers, \& Buswell, 1999), and the female sample in Study 2. Nonetheless, all patterns of results reported here, including the multivariate three-way interaction on self-esteem, Pillai's $=0.201 ; F(6,168)=3.125$, $p=.006, \eta=.010$, remained even when gender was not controlled. Preliminary examination of the self-esteem data also indicated that the assumptions of our planned analyses were met. All three subscales were approximately normally distributed (i.e., all multivariate skewness and kurtosis values were between +/- 1; George \& Mallery, 2010), no multivariate outliers were found (i.e., no values were $+/-3$ z-scores), and homogeneity of covariance across the groups was adequately assumed (Box's $M=79.25, p=.526$ ).

3. Preliminary examination of the mood data indicated that the positive affect subscale was normally distributed; however, the negative affect subscale was positively skewed (skewness $=1.571$; kurtosis $=2.765$ ), such that most participants reported relatively little negative affect, as has been previously and commonly reported (Merz et al., 2013). This skewness was also due in part to one outlier. Log-transformation of the negative affect variable corrected the non-normality of the distribution (skewness $=0.465$; kurtosis $=-$ 0.898). However, removal of the outlier and analyses using the log-transformation revealed the same pattern of results as with the untransformed data; thus, for ease of interpretation, results using untransformed data are presented here. 
Identity, religious spaces, and health 35

4. Blood pressure (BP) was also assessed in Study 2 as a potential threat response (consistent with our theoretical framework); however, no significant interactions emerged, likely due to the lack of a performance element in participants' responses. Given previous research suggesting that BP consistently differs between men and women (Reckelhoff, 2001), together with the relative unavailability of men in our student sample, only women were included in Study 2.

5. Preliminary examination of the Study 2 data indicated that all assumptions of the planned analyses (e.g., normality, homogeneity of variance) were met for each of the collective and personal self-esteem subscales as well as self-reported physical health. Two multivariate outliers were found on the private CSE subscale; however, removal of these cases did not alter the non-significant pattern of results already reported and are thus retained. As in Study 1, each of the negative affect subscales was positively skewed. Logtransformation of the negative affect variables corrected the skewness and kurtosis of the distributions; however, analyses using the log-transformed data again revealed no significant univariate or multivariate effects on mood. 